\title{
Lymphoepithelioma-like carcinoma of the renal pelvis: Pathological and therapeutic implications
}

\author{
Hemel Modi, MD;* Ian Beckley, MD;* Selina Bhattarai, MD; John Spencer, MD; Jon Cartledge, MD* \\ *Urology Department, St James's University Hospital, Leeds, UK; †Histopathology Department, St James's University Hospital, Leeds, UK; \$Radiology Deparment, St James's University Hospital, Leeds, UK
}

Cite as: Can Urol Assoc J 2013;7(9-10):e590-3. http://dx.doi.org/10.5489/cuaj.1545

Published online September 10, 2013.

\section{Abstract}

A 75-year-old woman presented with a presumed urothelial carcinoma of the right renal pelvis. A radical nephroureterectomy was carried out and histological analysis of the specimen revealed lymphoepithelioma-like carcinoma. This is the seventh reported case of this normally nasopharyngeal tumour found in the renal pelvis. These tumours have a distinct histological appearance comprising sheets of undifferentiated syncytial cells on a background of lymphoid stroma. We review the pathological features of lymphoepithelioma-like carcinoma and make arguments for managing these tumours in a similar way to urothelial carcinoma.

\section{Introduction}

Lymphoepithelioma is a malignant tumour found in the nasopharynx. When this tumour is found in other sites of the body, it is referred to as lymphoepithelioma-like carcinoma (LELC). LELC of the renal pelvis is extremely rare and, to our knowledge, this is the seventh reported case.

\section{Case report}

A 75-year-old woman presented with a 4-week history of painless visible hematuria. Abdominal examination was unremarkable with no tenderness or masses palpable. Urine cytology revealed atypical cells, suspicious for malignancy. Serum hemoglobin was $12.2 \mathrm{~g} / \mathrm{dL}$ and serum creatinine was $80 \mu \mathrm{mol} / \mathrm{L}$. A renal ultrasound scan demonstrated mild hydronephrosis of the right kidney. Flexible cystoscopy was performed which did not reveal any intravesical abnormality. The patient subsequently underwent a computed tomography $(\mathrm{CT})$ scan which demonstrated a lobulated
$4.5 \times 3.2-\mathrm{cm}$ enhancing mass within the right renal pelvis (Fig. 1). The appearances were suggestive of urothelial carcinoma. A 3-cm lymph node was identified adjacent to the inferior vena cava; however, there was no evidence of distant metastases. The patient subsequently underwent an uncomplicated laparoscopic right nephroureterectomy and was discharged on postoperative day 3.

Histological examination of the tumour specimen revealed an undifferentiated tumour composed of diffuse sheets of highly pleomorphic cells with scant cytoplasm, frequent mitotic activity and apoptosis. The tumour cells formed syncytial clusters (Fig. 2). The tumour was admixed with dense inflammatory infiltrate consisting of lymphocytes, plasma cells and macrophages (Fig. 3).

The epithelial component of the tumour was positive for cytokeratin AE1/AE3 (Fig. 4). Focally, there was evidence of urothelial dysplasia and carcinoma in situ supported by full thickness positivity for CK20 (Fig. 5). The final histological diagnosis was pT3 pN1 Mx lymphoepithelioma-like carcinoma of the renal pelvis.

At the 6-month follow-up, the patient remained well with no evidence of disease recurrence.

\section{Discussion}

Lymphoepithelioma is a common malignant tumour of the nasopharynx. It is occasionally seen at other sites, in which case it is referred to as LELC. These sites include the thymus gland, ${ }^{1}$ salivary glands, ${ }^{2}$ lungs, ${ }^{3}$ stomach $^{4}$ and, rarely, the urinary tract.

Most cases of LELC of the urinary tract have been found in the bladder, with around 40 reported cases. ${ }^{5}$ LELC of the bladder is more common in middle-aged men and accounts for $0.4 \%$ to $1.3 \%$ of all bladder carcinomas. ${ }^{5,6}$ There have been 7 cases of LELC found in the ureter and only 6 cases within the renal pelvis (Table 1). 


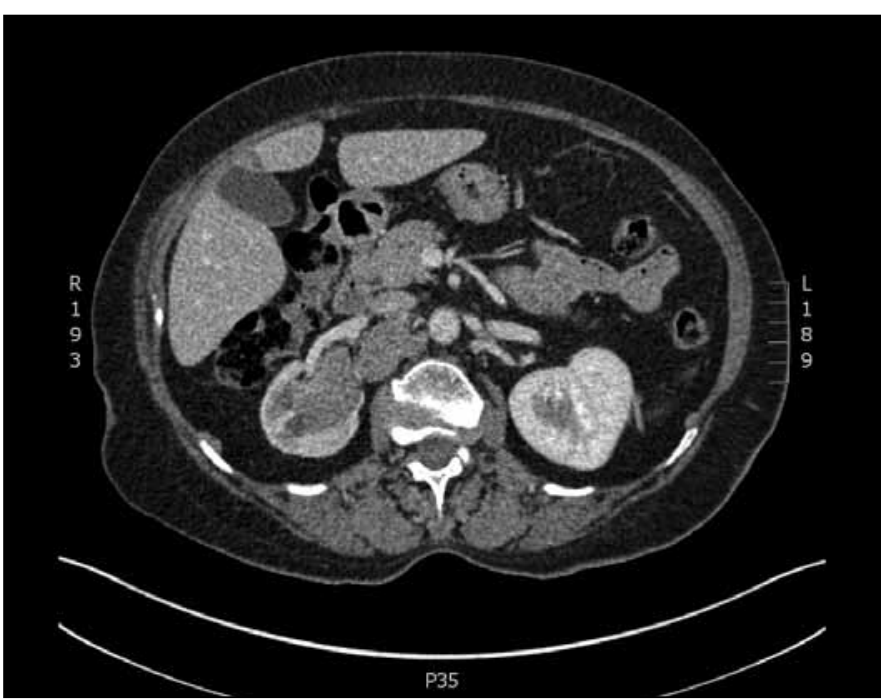

Fig 1. A computed tomography scan demonstrating an enhancing lesion arising from the right renal pelvis.

The World Health Organization's classification of urinary tract tumours describes LELC as a subgroup of urothelial carcinoma because it is derived from modified urothelial cells. ${ }^{5}$ On histological examination, LELC is made up of sheets of undifferentiated cells with pleomorphic nuclei. The cells take on a syncytial appearance due to the ill-defined borders of the cytoplasm. This cellular arrangement is on a background of lymphoid stroma consisting of lymphocytes and plasma cells. ${ }^{5}$ The epithelial component of the tumour typically stains with a number of cytokeratin (CK) markers, namely AE1/AE3, CK8, CK7 and CK20.,

Amin and colleagues classified LELC of the urinary bladder into 3 categories: pure $(100 \%$ LELC), predominant (more than $50 \%$ LELC) and focal (less than 50\% LELC). ${ }^{9}$ Where less than $100 \%$ LELC is seen, the remainder of the tumour usu-

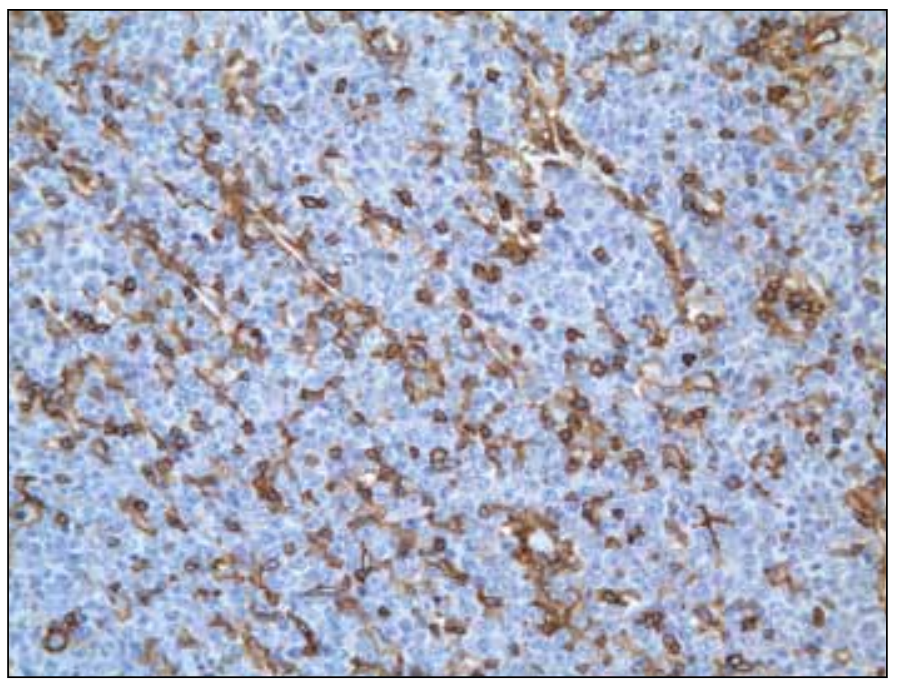

Fig. 3. CD45 positive inflammatory cells mixed with tumour cells.

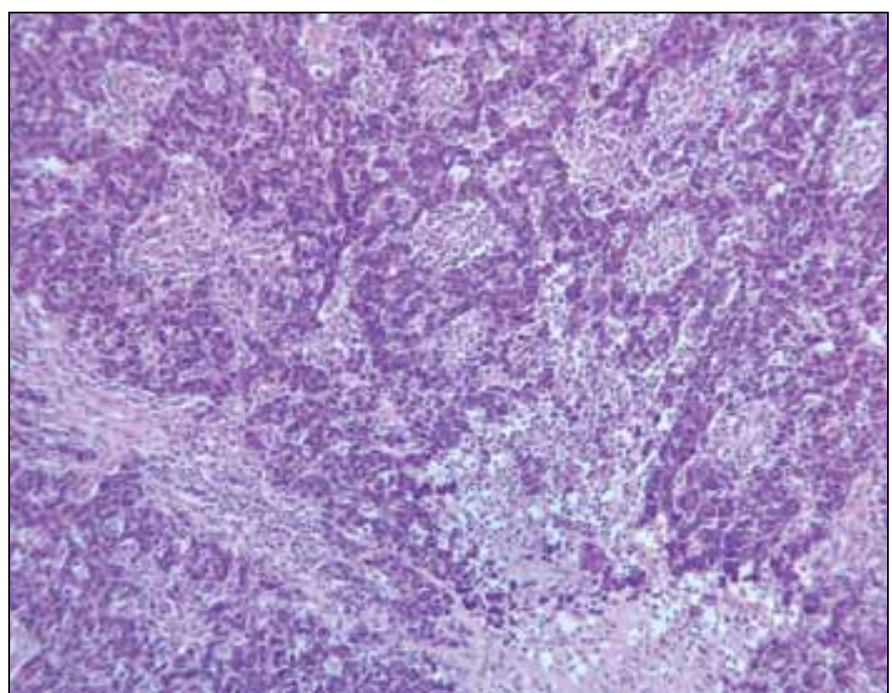

Fig. 2. Lymphoepithelioma-like carcinoma with mixed inflammatory cells forming syncytial clusters.

ally comprises classical urothelial carcinoma. Porcaro and colleagues conducted a literature review of 43 patients with LELC of the urinary bladder; they found that the survival rate was $93 \%$ for pure LELC (mean follow-up 48.1 months), 93\% for predominant LELC (mean follow-up 32 months), and $0 \%$ for focal LELC (mean follow-up 30.3 months). ${ }^{6}$ While this classification and prognosis relate to LELC of the urinary bladder, many of the reported cases of LELC of the renal pelvis have also been categorized in the literature using this taxonomy (Table 1). In line with this, the histological findings in our case were consistent with predominant LELC.

Unlike nasopharyngeal lymphoepithelioma, LELC of the urinary tract is not associated with the Epstein-Barr virus (EBV) on immunohistochemical analysis. ${ }^{10}$ Haga and colleagues observed that EBV-positive LELC tends to occur in

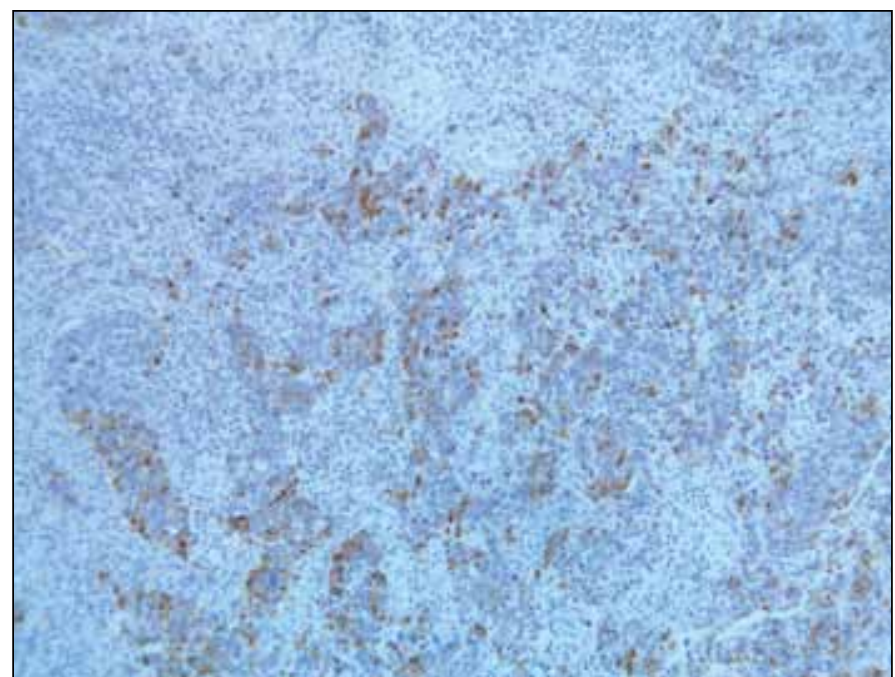

Fig. 4. Cytokeratin AE1/AE3 positivity within the tumour. 


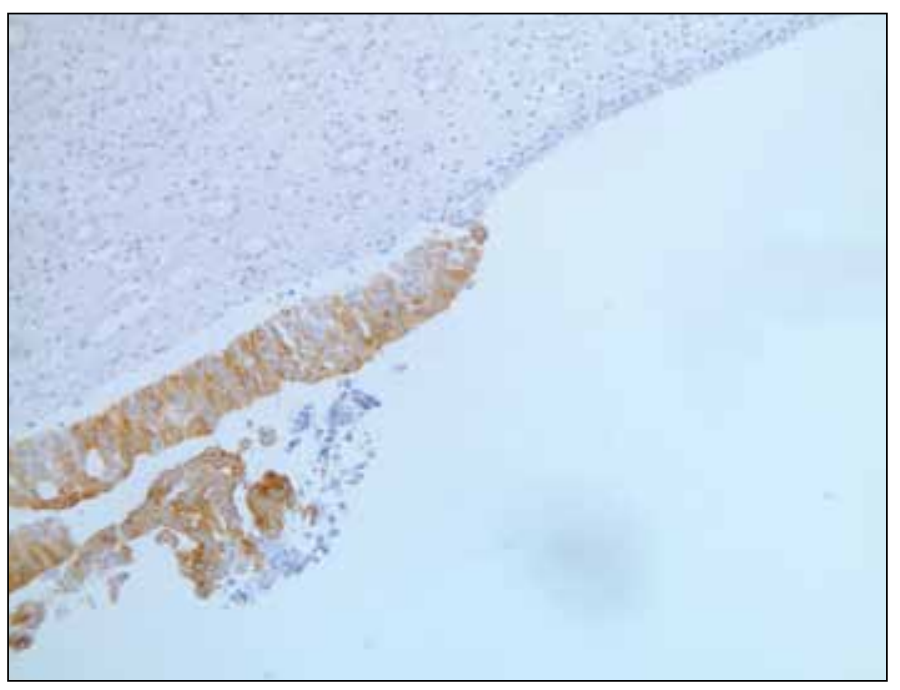

Fig. 5. Carcinoma-in-situ showing CK20 positivity.

organs that have a direct exposure to the external environment and EBV-negative tumours occur more often in internal organs. ${ }^{11}$ An alternative etiology for LELC of the urinary tract needs to therefore be considered. Mayer and colleagues proposed an exaggerated immune response as a possible mechanism. ${ }^{12}$

The main differential diagnoses of LELC include poorly differentiated squamous cell carcinoma, inflammatory lesions and lymphoma. ${ }^{5,13}$ Differentiation from lymphoma is achieved by recognizing the syncytial pattern of malignant cells with a dense lymphoid stromal background. ${ }^{8}$

Including our patient, there have only been 7 reported cases of LELC of the renal pelvis, the first described in 1998 (Table 1). ${ }^{14}$ Of these 7 patients, 5 were female and the mean age was 73 . Most patients presented with frank hematuria and most had an advanced stage (pT3) of disease. All tumours expressed one or more of CK7, CK15, CK20 and
AE1/AE3 and were negative for EBV. All patients were managed with radical surgery and 1 patient also had adjuvant radiotherapy. Two patients died with the disease after a median follow-up of 6 months.

Although there are no guidelines regarding the management of LELC of the renal pelvis due to the rarity of cases, it is interesting to note that from the case series (Table 1), 2 of the 3 patients who underwent radical nephrectomy alone died with the disease. However, all those who underwent radical nephroureterectomy had no evidence of disease on follow-up. This may support the theory that LELC of the urinary tract requires radical resection of the entire upper tract urothelium and is, therefore, related to urothelial carcinoma. This leads us to conclude that patients with LELC should undergo nephroureterectomy as the treatment of choice. This conclusion has been supported by Haga and colleagues; they advocated nephroureterectomy as the primary treatment with 6 monthly clinical and radiological follow-up. ${ }^{11}$

Lymphoepithelioma of the nasopharynx has been shown to be sensitive to chemotherapy. Rahima and colleagues showed that disease-free survival improved in patients treated with chemotherapy (cyclophosphamide, methotrexate plus either 5-fluorouracil or bleomycin), in addition to whole-neck irradiation, when compared with patients who received irradiation alone (77\% vs. $49.7 \%, p<0.05) .{ }^{15}$ LELC of the bladder has also been successfully treated with primary or adjuvant chemotherapy. In particular, a favourable outcome has been seen with cisplatin-based agents, which are commonly used in the treatment of urothelial carcinoma of the upper urinary tract. Dinney and colleagues found that 2 of their 3 patients with LELC of the bladder treated with primary cisplatin-based chemotherapy had no evidence of disease recurrence at the 5-year follow-up. ${ }^{16}$ Therefore we believe cisplatin-based chemotherapy may play an important role in the management of LELC of the renal pelvis.

Table 1. Characteristics of reported cases of lymphoepithelioma-like carcinoma of the renal pelvis

\begin{tabular}{|c|c|c|c|c|c|c|c|c|c|c|}
\hline Author & Year & Presentation & Age/gender & Stage & CK antigen & EBV-status & Classification & Treatment & Follow-up & Outcome \\
\hline Fukunaga $^{14}$ & 1998 & $\begin{array}{c}\text { Frank } \\
\text { hematuria }\end{array}$ & 70/M & Unknown & 7,20 & Negative & Pure & $\mathrm{RN}+\mathrm{RT}$ & 6 years & NED \\
\hline Cohen ${ }^{13}$ & 1999 & $\begin{array}{c}\text { Frank } \\
\text { hematuria, } \\
\text { loin pain }\end{array}$ & $79 / F$ & T3NOMO & AE1/AE3 & Negative & Unknown & NU & 6 months & NED \\
\hline $\begin{array}{l}\text { Perez- } \\
\text { Montiel }^{19}\end{array}$ & 2006 & Unknown & $72 / F$ & T3 & AE1/AE3 & Negative & Predominant & $\mathrm{RN}$ & 3 months & DWD \\
\hline $\begin{array}{l}\text { Perez- } \\
\text { Montiel }^{19}\end{array}$ & 2006 & Unknown & $68 / \mathrm{M}$ & T3 & AE1/AE3 & Negative & Focal & $\mathrm{RN}$ & 12 months & DWD \\
\hline $\mathrm{Haga}^{11}$ & 2007 & $\begin{array}{c}\text { Frank } \\
\text { hematuria }\end{array}$ & $75 / \mathrm{F}$ & T1N1M0 & Unknown & Negative & Pure & NU & 36 months & NED \\
\hline Yamada ${ }^{20}$ & 2007 & $\begin{array}{c}\text { Frank } \\
\text { hematuria }\end{array}$ & $75 / F$ & T3NOMO & 15 & Negative & Unknown & RN & 6 months & NED \\
\hline $\begin{array}{l}\text { Present } \\
\text { case }\end{array}$ & 2011 & $\begin{array}{c}\text { Frank } \\
\text { hematuria }\end{array}$ & $75 / F$ & T3N1M0 & $\begin{array}{c}20 \\
\text { AE } 1 / A E 3\end{array}$ & Not tested & Predominant & NU & 6 months & NED \\
\hline
\end{tabular}


The recurrence rate within the bladder after treatment of classical urothelial carcinoma of the upper urinary tract varies from $15 \%$ to $50 \% .^{17}$ Therefore, if LELC of the kidney is considered a form of urothelial carcinoma, then close surveillance for metachronous bladder tumours is essential. The European Association of Urology guidelines for the management of upper tract urothelial carcinoma recommend a minimum follow-up period of 5 years. ${ }^{18}$ During this time, cystoscopy and urine cytology testing is performed at 3 months and annually thereafter. We consider this to also be an appropriate follow-up protocol for LELC of the renal pelvis given its similarity to urothelial carcinoma.

\section{Conclusion}

LELC is a malignant tumour found very rarely in the upper urinary tract, with only 6 previously reported cases within the renal pelvis. As with any upper tract tumour, it commonly presents with visible painless hematuria and investigations should be those of any suspected renal neoplasm.

Histological diagnosis of LELC requires identification of a particular appearance and arrangement of tumour cells and the presence of specific antigens. It can be considered as a subgroup of urothelial carcinoma as both types of tumour contain modified urothelial cells. Unlike lymphoepithelioma of the nasopharynx, however, LELC of the urinary tract is not related to EBV.

Based on literature regarding the management of LELC at other sites and that of urothelial carcinoma of the kidney, we conclude that LELC of the kidney should be treated with nephroureterectomy with consideration given to neoadjuvant or adjuvant cisplatin-based chemotherapy. Follow-up measures should include regular cystoscopic examination and urine cytological analysis.

However, as there is little data on LELC of the renal pelvis, a larger case series with longer follow-up is needed to further evaluate the behaviour of this tumour and determine the optimal management regimen and disease prognosis.

Competing interests: None declared.

This paper has been peer-reviewed.

\section{References}

1. Ritter JH, Wick MR. Primary carcinoma of the thymus gland. Semin Diagn Pathol 1999;16:18-31.

2. Saw D, Lau WH, Ho JH, et al. Malignant lymphoepithelial lesion of the salivary glands. Hum Pathol 1986;17:914-23. http://dx.doi.org/10.1016/S0046-8177(86)80641-4

3. Butler AE, Colby TV, Weiss LM. Lymphoepithelioma-like carcinoma of the lung. Am I Surg Pathol 1989;13:629-32. http://dx.doi.org/10.1097/00000478-198908000-00002

4. Wang HH, Wu MS, Shun CT, et al. Lymphoepithelioma-like carcinoma of the stomach: a subset of gastric carcinoma with distinct clinicopathological features and high prevalence of Epstein-Barr virus infection. Hepatogastroenterology 1999;46:1214-9.

5. Eble JN, Sauter G, Epstein II, et al. World Health Organization Classification of Tumours. Pathology and Genetics of Tumours of the Urinary System and Male Genital Organs. IARC Press: Lyon, France; 2004.

6. Porcaro AB, Gilioli E, Migliorini F, et al. Primary lymphoepithelioma-like carcinoma of the urinary bladder: Report of one case with review and update of the literature after a pooled analysis of 43 patients. Int Urol Nephrol 2003;35:99-106. http://dx.doi.org/10.1023/A:1025981106561

7. Holmang S, Borghede G, Johansson SL. Bladder carcinoma with lymphoepithelioma-like differentiation: a report of 9 cases. J Urol 1998;159:779-82. http://dx.doi.org/10.1016/S0022-5347(01)63727-3

8. Lopez-Beltran A, Luque RJ, Vicioso L, et al. Lymphoepithelioma-like carcinoma of the urinary bladder: a clinicopathologic study of 13 cases. Virchows Arch 2001;438:552-7. http://dx.doi.org/10.1007/ s004280000378

9. Amin MB, Ro JY, Lee KM, et al. Lymphoepithelioma-like carcinoma of the urinary bladder. Am J Surg Pathol 1994;18:466-73. http://dx.doi.org/10.1097/00000478-199405000-00005

10. Terai A, Terada N, Ichioka K, et al. Lymphoepithelioma-like carcinoma of the ureters. Urology 2005;66:1109. http://dx.doi.org/10.1016/j.urology.2005.05.038

11. Haga K, Aoyagi T, Kashiwagi A, et al. Lymphoepithelioma-like carcinoma of the renal pelvis. Int I Urol 2007;14:851-3. htrp://dx.doi.org/10.1111/i.1442-2042.2007.01846.x

12. Mayer EK, Beckley I, Winkler MH. Lymphoepithelioma-like carcinoma of the urinary bladder-diagnostic and clinical implications. Nat Clin Pract Urol 2007;4:167-71. http://dx.doi.org/10.1038/ncpuro0725

13. Cohen RJ, Stanley JC, Dawkins HJS. Lymphoepithelioma-like carcinoma of the renal pelvis. Pathology 1999;31:434-5. http://dx.doi.org/10.1080/003130299104891

14. Fukunaga $M$, Ushigome $S$. Lymphoepithelioma-like carcinoma of the renal pelvis: a case report with immunohistochemical analysis and in situ hybridization for the Epstein-Barr viral genome. Mod Pathol 1998;11:1252-6.

15. Rahima M, Rakowsky E, Barzilay J, et al. Carcinoma of the nasopharynx. An analysis of 91 cases and a comparison of differing treatment approaches. Cancer 1986;58:843-9. http://dx.doi. org/10.1002/1097-0142(19860815)58:4<843::AID-CNCR2820580406>3.0.C0;2-M

16. Dinney CP, Ro JY, Babaian RJ, et al. Lymphoepithelioma of the bladder: a clinicopathological study of 3 cases. J Urol 1993;149:840-1.

17. Azemar MD, Comperat E, Richard F, et al. Bladder recurrence after surgery for upper urinary tract urothelial cell carcinoma: frequency, risk factors and surveillance. Urol Oncol 2011;29:130-6. http://dx.doi. org/10.1016/j.urolonc.2009.06.003

18. Rouprêt $M$, Zigeuner $R$, Palou J, et al. European guidelines for the diagnosis and management of upper urinary tract urothelial cell carcinomas: 2011 update. Eur Urol 2011;59:584-94. http://dx.doi. org/10.1016/i.eururo.2010.12.042

19. Perez-Montiel $D$, Wakely PE, Hes 0 , et al. High-grade urothelial carcinoma of the renal pelvis: clinicopathologic study of 108 cases with emphasis on unusual morphologic variants. Mod Pathol 2006; 19:494-503. http://dx.doi.org/10.1038/modpathol.3800559

20. Yamada Y, Fujimura T, Yamaguchi T, et al. Lymphoepithelioma-like carcinoma of the renal pelvis. Int J Urol 2007;14:1093-4. htrp://dx.doi.org/10.1111/i.1442-2042.2007.01897.x

Correspondence: Mr. Hemel Modi, Flat 7 Hungate House, 896 Hessle Road, Hull, UK HU4 6SA; hemelmodi@doctors.org.uk 